\title{
Menores inmigrantes vulnerados por el gobierno estadounidense. Atrocidades y omisiones de las políticas públicas
}

\section{Minor immigrants vulnerates by the US government. Atrocities and omissions of public policies}

\author{
Miguel Moctezuma-Longoria
}

\author{
Unidad Académica en Estudios del Desarrollo de la Universidad \\ Autónoma de Zacatecas, México
}

\begin{abstract}
Resumen
El propósito de este artículo consiste en poner de manifiesto que la vulnerabilidad y los riesgos a que son sometidos los menores migrantes "no acompañados", constituye una atrocidad que nada tiene que ver con la vulnerabilidad de las personas cuando se convierte en política pública de un Estado que interviene con todo su poder. Por un lado, desde Estados Unidos se trata de políticas activas, y por otro, de políticas omisas desde México, que atentan contra la dignidad humana, y que en la mayoría de los casos se fundamentan en la renuncia de las obligaciones sociales del Estado para con las personas, cuyos derechos les son arrebatados o negados, como sucede con el derecho a la vida, el amor, la protección y la seguridad íntima que provee el vinculo con la familia $y / o$ parentela.
\end{abstract}

Palabras clave: Crear vulnerabilidad, separación de menores migrantes, excesos de política pública y defensa de derechos civiles y humanos.

\section{Abstract}

The purpose of this article is to show that vulnerability and the risks to which unaccompanied migrant minors are subjected constitute an atrocity that has nothing to do with the vulnerability of people when it becomes a public policy of a State that intervenes with all its power. On the one hand, the United States deals with active policies, and on the other hand, with policies that are omitted from Mexico, that undermine human dignity, and that in most cases are based on the renunciation of the State's social obligations to with people, whose rights are taken away or denied, as is the case with the right to life, love, protection and the intimate security provided by the link with the family and / or family.

Keywords: Create vulnerability, separation of minors migrant, excess of public policy and defense of civil and human rights. 


\section{INTRODUCCIÓN}

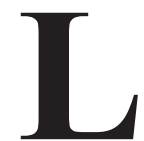

a vulnerabilidad de los menores migrantes y la exposición a los riesgos a los que aquí nos referiremos no son naturales, sino sociales; mientras los primeros los provee la naturaleza, los segundos son creados por el Estado, e incluso, cuando la misma sociedad los asume como suyos son en gran medida resultado prefigurado e inducido por los estrategas del ejercicio del poder de quienes buscan dar sentido a las mismas. Esta vulnerabilidad creada por la implementación de las políticas públicas se manifiesta con mayor crudeza en las mujeres y en los grupos étnicos de los inmigrantes, pero se exacerba cuando se trata de niños y niñas migrantes que no rebasan los 12 años, e incluso, cuando son menores de cinco años, diez es todavía más lesivo. Por supuesto, aunque se habla poco de esto, el drama de los menores lo viven asimismo sus padres con miedo, angustia e impotencia. Estas manifestaciones humanas nada tienen que ver con el estatus migratorio, simplemente las experimenta cualquier persona que es sometida a esas condiciones. El conjunto de estas experiencias terribles a que son sometidos los padres y sus hijos pueden ser descritas como la pérdida de la seguridad ontológica (Giddens, 1993: 142 y 144). Se trata de un desacoplamiento personal y familiar tal que, cuando un menor migrante se pierde o muere en el intento de llegar a Estados Unidos provoca en los seres queridos más cercanos un estado de estrés y de sufrimiento próximo a la locura, transitando hacia un duelo sin fin sobre todo si el migrante termina desaparecido y se le busca desesperadamente sin éxito.

La pérdida de la seguridad ontológica se advierte asimismo en aquellos migrantes adultos que al intentar cruzar la frontera experimentan situaciones límite que llegan a poner en duda la vida misma, los cuales han sido registrados en los exvotos religiosos implorando un milagro divino (Martínez, 2010). Y es que, para todo creyente, cuando terminan las certezas, ante la ausencia de políticas públicas para su protección y seguridad, lo único que queda es la fe de un poder sobrenatural.

El drama de la pérdida de la seguridad ontológica entre menores migrantes y familiares ha cobrado realce, al mostrar por la prensa estadounidense las condiciones en que los mismos se encuentran en los albergues al ser separados de sus padres sin su consentimiento, y al enterarse que esa separación podría conducir con frecuencia a la imposibilidad del rencuentro entre padres e hijos, y por tanto, a que éstos sean dados en adopción 
a terceros desconocidos; es decir, a vivir la pérdida de la seguridad ontológica, tal como aquí se postula. A pesar del dramatismo de los medios de comunicación, esto no es nuevo, sólo que el discurso antiinmigrante del Presidente Trump lo ha visibilizado ampliamente como un mecanismo de poder cuyo objetivo pretende crear terror como política de Estado y desalentar con ello la inmigración. Este terror se viene implementando asimismo al deportar a los padres y separar a las familias. Un enfoque reciente que inspira esta mirada es el de la nuda vida a que son sometidas las personas cuando el representante del poder ejecutivo de un país concentra al máximo el poder, a tal al grado de reducir a la persona a simple cuerpo, sin derecho alguno (Agamben, 2004). Esto es lo que se devela en la política del estado de excepción que se esconde detrás del discurso de la emergencia nacional que actualmente promueve el Presidente Donald Trump y que choca con la tradición estadounidense de dar asilo o protección a quienes llegan como migrantes a su territorio perseguidos o amenazados en sus países de origen.

El propósito de este artículo consiste en poner de manifiesto que la vulnerabilidad y los riesgos a que son sometidos los menores migrantes "no acompañados", (llamados así al separarlos mayoritariamente de sus padres) constituye una atrocidad que nada tiene que ver con la vulnerabilidad de las personas cuando se convierte en política pública de un Estado que interviene con todo su poder, en contra de los seres humanos. Por un lado, desde Estados Unidos se trata de políticas activas, y por otro, de políticas omisas desde México, que atentan contra la dignidad humana, y que en la mayoría de los casos se fundamentan en la renuncia de las obligaciones sociales del Estado liberal para con las personas, dirigidas hacia seres humanos cuyos derechos les son arrebatados o negados, como sucede con el derecho a la vida, el amor, la protección y la seguridad íntima que provee el vinculo con la familia y/o parentela.

El segundo propósito de esta reflexión pretende demostrar la existencia de un lenguaje artificioso y de complicidad por parte de las autoridades de los gobiernos de Estados Unidos y México, los cuales buscan justificar esa política, ocultando los hechos en la puesta en marcha de programas de política pública cuyo lenguaje por parte de Estados Unidos se lee en los siguientes términos: "protección y seguridad de la frontera", "menores inmigrantes no acompañados", programa de "custodia de menores", "deportación de criminales", y por parte de México "repatriación humanitaria".

Las interrogantes que nos guían son estas: ¿Por qué la frontera de Estados Unidos debe ser protegida frente a los inmigrantes en términos de 
seguridad nacional?, y si realmente está amenazada la seguridad nacional ¿Qué tienen que ver en ello los menores migrantes para separarlos de sus acompañantes? ¿Por qué los migrantes, independientemente de su estatus legal cuando son deportados no pueden decidir por sus hijos? O a la inversa, ¿Por qué los menores no tienen derecho a permanecer con sus padres cuando éstos son indocumentados y son acusados de delincuentes sólo porque fueron aprehendidos cruzando varias veces la frontera?, y ¿Por qué el gobierno mexicano dice que desde 2004 cuenta con un programa de repatriación humanitaria, cuando sólo recibe a los deportados en territorio mexicano y ocasionalmente apoya su traslado hasta sus entidades de origen?

En todo esto, la investigación social se ha dejado confundir por el lenguaje de los gobiernos, además de mostrar un retraso respecto de los cambios que experimenta la simultaneidad y el doble sentido que tiene la migración México-Estados Unidos y Estados Unidos-México (Moctezuma, 2013). Por supuesto, es inevitable que en los estudios de la migración tropecemos con conceptos jurídicos que requieren ser analizados cuidadosamente, elaborando conceptos científicos. En todo caso, se trata de dos tipos distintos de hermenéutica: la primera se refiere a la implementación de las políticas de Estado, mientras que la segunda da cuenta de la racionalidad de la ciencia.

\section{MenORES Migrantes "NO ACOMPAÑAdOS"}

Empecemos cuestionando la denominación de menores migrantes "no acompañados", mostrando que se trata de una separación arbitraria de sus familiares, amigos o conocidos implementada por un Estado, cuando son descubiertos cruzando la frontera y son aprehendidos por las autoridades estadounidenses. Los hechos son así: si un menor migrante al ser detenido declara que va acompañado de algún familiar o amigo, en ambos casos, la primera experiencia será la separación entre menores y adultos, y, en el segundo, será inevitable que los amigos sean declarados traficantes de indocumentados y sometidos a castigos y penas de cárcel de varios años. En esta acción es donde el gobierno estadounidense crea el vía crucis de los menores migrantes.

\section{¿Cuántos y de dónde son?}


En diez años fiscales que abarca de octubre de 2009 a julio de 2018 se presentaron en Estados Unidos 203,079 eventos de intercepción y aprehensión de menores inmigrantes centroamericanos y 127,951 menores migrantes mexicanos; es decir, los menores centroamericanos representaban 61.3 por ciento y los mexicanos 38.7 por ciento, cuyo promedio anual fue 23,008 y 12,795 respectivamente; es decir, la mayoría de los menores migrantes son de los países de El Salvador, Guatemala y Honduras, no obstante, no por eso el problema para México es menor. El año fiscal en el que hubo mayores aprehensiones fue 2014, lo que coincide con la crisis por la saturación de los albergues existentes y por la improvisación de algunos de ellos en los campos militares (Tabla 1).

A partir de los datos oficiales que arroja la información de las autoridades estadounidenses podemos considerar claramente dos momentos: 20092014 y 2015-2018. El primero se distingue por un crecimiento explosivo en las aprehensiones en el territorio estadounidense de los menores migrantes de origen centroamericano hasta alcanzar su nivel más alto en 2014, mientras que México en 2009 aportaba la mayor cantidad de los cuatro países, en 2014, aunque su flujo se mantenía constante, su proporción quedaba por debajo de los tres países centroamericanos. El segundo momento es muy errático, pero su tendencia es descendente, con excepción de Guatemala, seguido por Honduras que son los dos países que aportan la mayor cantidad de menores migrantes aprehendidos; en cambio, México, termina en 2018 con una clara disminución de sus menores migrantes, respecto de 2009 y 2014 (Figura 1).

Según información de la Secretaría de Gobernación en 2015, de los 11,667 eventos que se refieren a menores migrantes deportados a México, las entidades que aportaron una mayor proporción fueron: Oaxaca (12.5 por ciento), Guerrero (10.1 por ciento), Sonora (diez por ciento), Tamaulipas (9.4 por ciento), Michoacán (6.4 por ciento) y Guanajuato (5.8 por ciento) (Lorenzen, 2016); es decir, en 2015 seis entidades aportaron aproximadamente 54.2 por ciento del total. Los estados de Oaxaca y Guerrero y en menor medida Michoacán son los que más preocupan por su vulnerabilidad por ser migrantes indígenas.

Otro de los aspectos que destacan entre 2015-2018, relacionados con la presencia de los menores migrantes es el registro de aprehensiones de migrantes de edades distintas que son parte de una misma familia. Su presencia es realmente muy alta y debe de ser parte de los distintos flujos que presenta la migración internacional. 


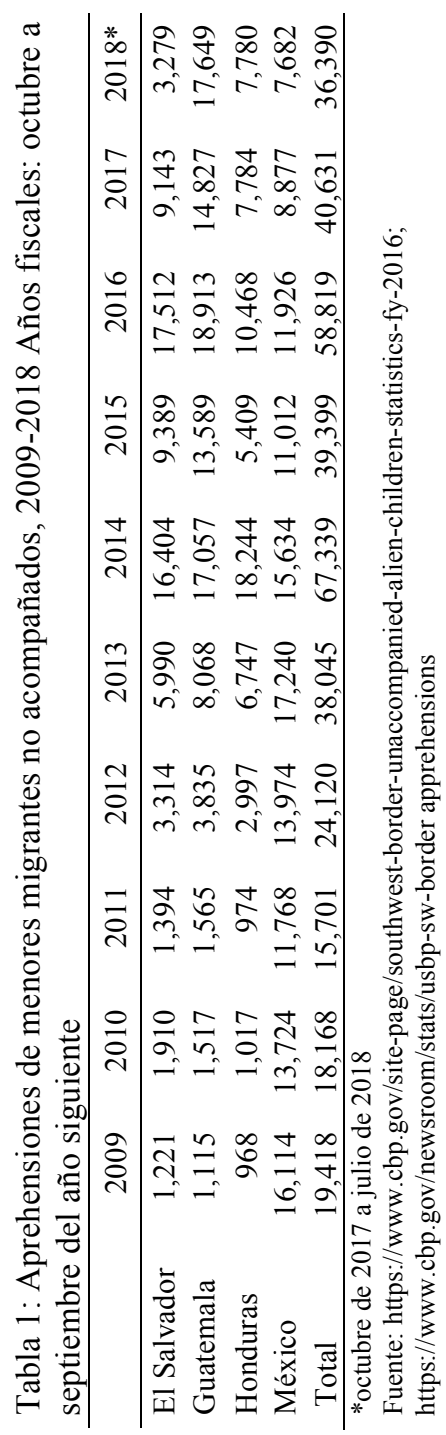


Figura 1: Menores Migrantes no Acompañados Aprehendidos el ICE, 2009-2018

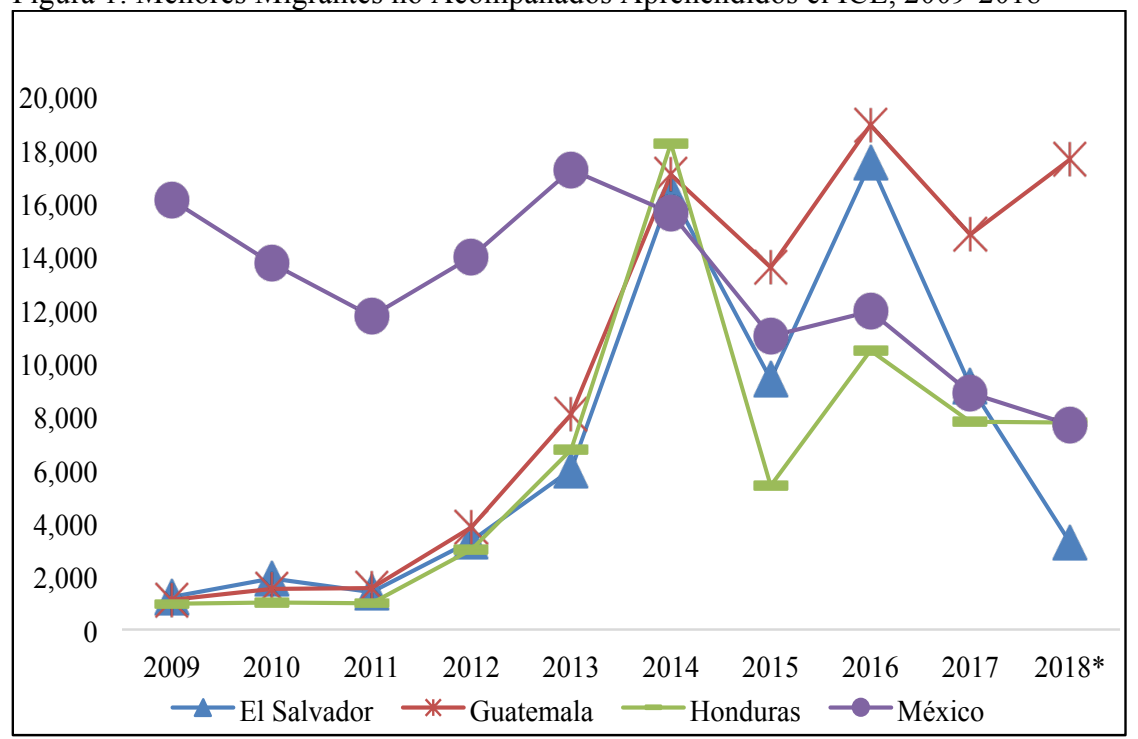

Fuente: https:/www.cbp.gov/site-page/southwest-border-unaccompanied-alien-children-statistics-fy-2016; https://www.cbp.gov/newsroom/stats/usbp-sw-border apprehensions

En este caso, mientras Guatemala y Honduras representan los dos países con mayor crecimiento e incidencia, México muestra una presencia realmente marginal y en claro descenso. Estas tendencias, indican que los menores migrantes de origen centroamericano experimentan mayores presiones sociales y peligros en sus países, respecto de los mexicanos, que los obligan a emigrar (Tabla 2).

Hasta aquí resulta obvia la necesidad de promover una alianza estratégica con los gobiernos de los países centroamericanos con el objetivo de abordar juntos la defensa de los menores migrantes; esto sin embargo, exige de México comprometerse a hacer su parte respecto de los menores migrantes que se desplazan por el territorio nacional con destino hacia Estados Unidos.

Cabe advertir que las cantidades dadas no son exactas, primero, porque las aprehensiones y las deportaciones son eventos y no inmigrantes; es decir, un mismo inmigrantes puede ser detenido y registrado varias veces, sobre todo en el caso de los menores mexicanos que son deportados a la zona fronteriza de México y entregados a las autoridades mexicanas, algunos de ellos vuelven a intentar cruzar y son reaprehendidos por segunda o tercera vez en territorio estadounidense. Cuando esto sucede, son detenidos como reincidentes. 
Tabla 2: Aprehensiones de familias de migrantes, 2015-2018. Años fiscales octubre a septiembre del año siguiente

\begin{tabular}{lrrrr}
\hline & 2015 & 2016 & 2017 & $2018^{*}$ \\
\hline El Salvador & 10,872 & 27,114 & 24,122 & 8,462 \\
Guatemala & 12,820 & 23,067 & 24,657 & 33,389 \\
Honduras & 10,671 & 20,226 & 22,366 & 24,451 \\
México & 4,276 & 3,481 & 2,217 & 1,565 \\
& 38,639 & 73,888 & 73,362 & 67,867 \\
\hline
\end{tabular}

*octubre de 2017 a julio de 2018.

Fuente: https://www.cbp.gov/newsroom/stats/usbp-sw-border apprehensions

La otra observación, como ya se empieza a reconocer, no se trata de menores inmigrantes "no acompañados", pues, el trabajo de campo demuestra fehacientemente que entre ellos hay menores que van acompañados de sus padres, familiares o amigos y al ser aprehendidos por los agentes de inmigración son separados de ellos. Y es que el propio sistema de captura conduce a la separación de los menores, pues si uno de ellos cuenta con redes de solidaridad y reconoce que va acompañado, los agentes de inmigración terminan acusando al acompañante de tráfico de indocumentados; así que no hay más opción que mentir o callar. Esta práctica termina produciendo vulnerabilidad y por tanto, su consecuencia inmediata es el aumento de los riesgos a que son sometidos los menores al ser separados de sus redes sociales y de sus padres o familiares cercanos; entonces, de surgir la pérdida de la seguridad ontológica, nada tiene que ver con la predisposición personal a ella, sino que es resultado de dicha política. Pero, lo realmente infundado es que no existe nada que indique que los inmigrantes sean un peligro para la seguridad de Estados Unidos y que éste peligro desaparezca o disminuya con la separación de los menores respecto de los mayores. Sobre esta afirmación existen asimismo suficientes evidencias que prueban la frecuente separación de las esposas en 2012 respecto de sus cónyuges y de hermanas y hermanos (Ángel del et al., 2012: 37-38). Por supuesto, aunque en este caso se trata de mayores de edad, nada justifica que el gobierno estadounidense separe a hombres y mujeres cuando son cónyuges o hermanos. Sólo debemos imaginar el sufrimiento expresado en impotencia, miedo, ira e incertidumbre que experimenta un migrante cuando va al cuidado de un menor o de su cónyuge o familiar y es separado violentamente de ellos. Por supuesto, si a esto sumamos la incomunicación a que son duramente sometidos, en ambos casos los costos humanos son terribles. 
Con frecuencia quienes acompañan a los menores son también amigos, vecinos o miembros de una misma comunidad que actúan como redes sociales. $\mathrm{Y}$ es que ante los peligros, las redes sociales de los migrantes funcionan como solidaridad y protección; por tanto nada tienen que ver con el llamado tráfico de indocumentados. Por esa razón es importante exigir por las autoridades consulares de México la distinción entre redes de migrantes y relaciones de otro tipo. Por lo demás, entre más peligros haya que sortear durante la travesía a territorio estadounidense, las redes sociales se hacen más necesarias.

Otro de los aspectos que inciden en la vulnerabilidad y en el incremento de los riesgos a partir de 2012 en adelante, es la prevalencia de niñas, además de su corta edad, rasgos ambos que están actualmente en los registros estadounidenses entre los de mayor crecimiento. Y es que como se decía anteriormente, la vulnerabilidad creada por el propio Estado no tiene justificación alguna cuando los menores son indefensos por su corta edad, más si son niñas. Así, de octubre de 2013 a mayo de 2014 fueron registrados 785 menores de cinco años detenidos por el Immigration and Customs Enforcement ${ }^{1}$ Sólo bastará preguntarse a partir de las imágenes recientes de los medios de comunicación qué es lo que puede suceder cuando una o un menor de cinco años es separada(o) de sus padres en territorio estadounidense, ¿podrán comunicar cómo se llama?, o ¿de dónde proceden?, o ¿quiénes son sus padres? El mostrar estas cifras debiera de ser suficiente para una intervención directa desde México (Figura 2).

Al momento de redactar estas líneas, la prensa estadounidense se ha encargado de mostrar reiteradamente las imágenes de terror de los menores inmigrantes separados de sus padres, recluidos en albergues, clamando piedad para encontrarse con sus seres queridos. Pero en lugar de atender sus súplicas, varias fuentes han denunciado la peligrosa aplicación de psicotrópicos a los menores con el objetivo de que dejen de molestar. ${ }^{2}$ Las consecuencias de estos y otros hechos, ya ha provocado la muerte de menores centroamericanos que estaban bajo la custodia del Servicio de Inmigración y Control de Aduanas(ICE) perteneciente al Departamento de Seguridad Nacional (DHS).

\footnotetext{
${ }^{1} \mathrm{http}: / /$ www.pewresearch.org/fact-tank/2014/07/22/children-12-and-under-are-fastest-growinggroup-of-unaccompanied-minors-at-u-s-border/

${ }_{2} \mathrm{http}: /$ queenslatino.com/menores-inmigrantes-inyectados-inmigracion-sicotropicos/; $\mathrm{https}: / /$ www.revealnews.org/blog/immigrant-children-forcibly-injected-with-drugs-lawsuit-claims/
} 
Figura 2: Aprehensiones en Estados Unidos de Menores Migrantes

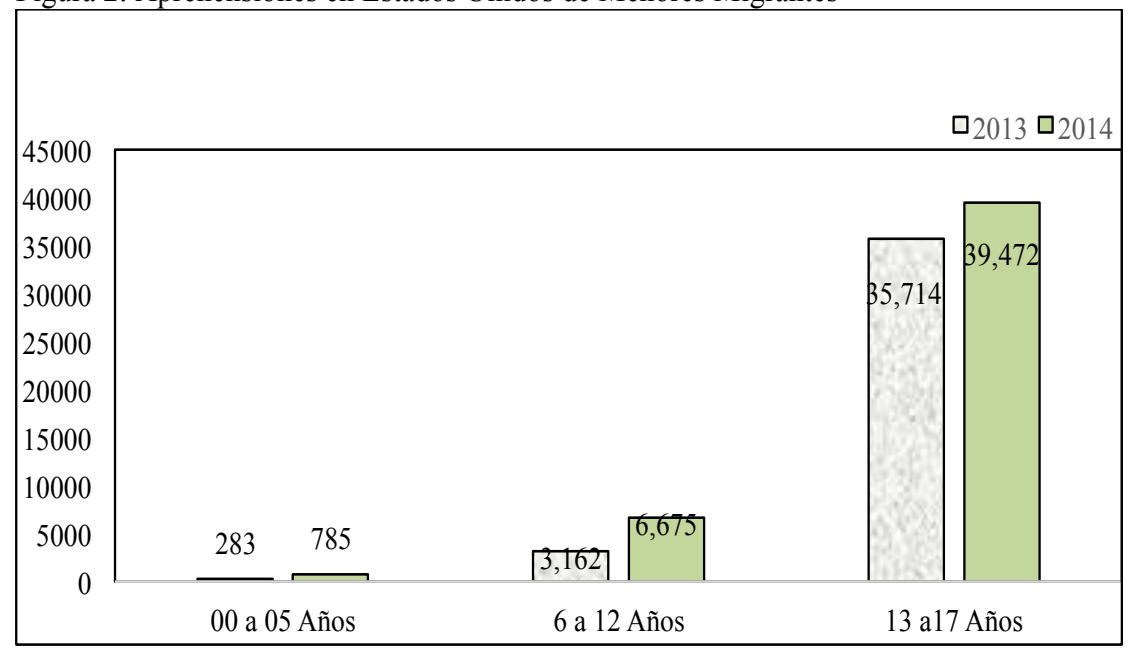

Año Fiscal 2013 (Octubre 01, 2012 a Septiembre 31 de 2013); Año Fiscal 2014 (Octubre 01, 2013 a Mayo 31 de 2014).

Fuente: Pew Center Analysis of U. S. Customs and Border Protection, Enforcement Integrated Database records.

Pero, no todo son malas noticias, existe un antecedente por lo menos en el sentido de otorgar el estatus de refugiados a los menores que llegan a Estados Unidos huyendo de los peligros en sus países de origen. En efecto, en 2008 el Congreso de Estados Unidos reconoció que las deportaciones expeditas de menores "no acompañados" se estaban haciendo sin revisar los peligros a los que están expuestos. Esto sirvió para aprobar una propuesta de ley que hasta la fecha sigue siendo letra muerta, pero que es necesario refrendar:

...La Ley sobre Protección de las Víctimas de Trata del 2008, (TVPRA) ordenó que el DHS (Departamento de Seguridad Nacional), entrevistara a cada niño, niña o adolescente sin compañía mexicano, para tomar la determinación de que (i) no sea una víctima potencial de tráfico o trata de personas, (ii) no tenga posibilidad de solicitar asilo, y (iii) que voluntariamente pueda y quiera regresar a su hogar en su país de origen. A menos de que todas estas preguntas se respondan de una manera afirmativa, el menor no debe ser regresado inmediatamente a México, sino que debe permanecer para ser evaluado y que pueda reclamar protección en los Estados Unidos (Appleseed, 2011).

Esta ley reconoce que existen menores que debieran de ser tratados cuidadosamente y en caso de estar en grave peligro otorgarles el estatus de refugiados; es decir, lo peor es que se tiene conciencia del peligro que 
corren estos menores y no se actúa en consecuencia. Pero, como ya se dijo, la inmigración es tratada en cada caso como un problema directo entre el Estado y las personas y no como una situación estructural que implica responsabilidades de dos países y dos Estados (Castañeda, 2012: 111-112).

En esta misma lógica existe un conflicto entre la tradición y vigencia de la ley sobre el derecho de asilo en Estados Unidos, que ha salido a relucir a raíz de la presencia de migrantes que forman parte del éxodo de centroamericanos. Por un lado, el Presidente Donald Trump pretende imponer el estado de excepción desconociendo la existencia de las leyes a través de una "orden ejecutiva" en contra del asilo de aquellos inmigrantes que ingresan al país o pretenden hacerlo de manera indocumentada; y por otro, El Juez de Distrito Jon Tigar, en San Francisco, al revisar esta situación emite un fallo contra de esa iniciativa presidencial. Esto mismo ha sucedido con los intentos de desconocer derechos a los dreamers y con el intento de desconocer el derecho a la nacionalidad y la ciudadanía a los hijos de inmigrantes indocumentados nacidos en territorio estadounidense. Se trata de dos tipos de concepciones de Estado en disputa y que el mismo Donald Trump clarifica cuando afirma que el mencionado juez es simpatizante del expresidente Barack Obama.

Asimismo, además de la mayor vulnerabilidad y riesgo que produce la separación de estos menores de sus familiares, lo trágico es que cuando son capturados y deportados a México, el Instituto Nacional de Migración oculta los hechos al llamarles "repatriados" como parte de un programa humanitario. Es cierto que no todos pasan por la decisión de un Juez de inmigración, quien ordena su deportación, pero, nadie ignora que son obligados a elegir entre el proceso legal y la deportación "voluntaria"; es decir, lo que tenemos son dos tipos de deportaciones, una mandatada por el sistema judicial y la otra implementada de facto. Por supuesto, esto nada tiene que ver con la repatriación, ya que los deportados ya se encuentran en su patria.

\section{LOS ALBERGUES ESTADOUNIDENSES ${ }^{3}$}

Por lo que toca a la observación participante, el encuentro oficial por invitación expresa de los agentes de inmigración de la Patrol Border en El Paso, Texas me dio acceso a una experiencia impactante y dolorosa: estuve frente a un menor recién aprehendido, que en esa fecha contaba con 16 años, edad similar a la que entonces tenía mi hijo menor de quien me

\footnotetext{
${ }^{3}$ Visita "oficial" a la Frontera México-Estados Unidos, invitación a un reducido grupos de académicos mexicanos por la Embajada Americana en Monterrey, durante los días 18-24 de febrero de 2007.
} 
interrogué seriamente sobre la posibilidad de que él fuera un indocumentado más como sucede tan frecuentemente en la entidad zacatecana. Y es que lo relacioné con otros tantos jóvenes zacatecanos que no encuentran alternativas para su desarrollo y a esa corta edad se involucran en los flujos de la migración internacional. En efecto, comparando el mismo grupo de edades para dos momentos distintos, la Encuesta Censal de 2015, con respecto Censo General de Población y Vivienda de 2010 registra un déficit importante para México de 167,640 habitantes entre las edades de 14 a 19 años (INEGI, 2010; INEGI, 2015); es decir, la mayor parte de ellos son menores de edad. En comparación con 2000 versus 2005, éstas cifras son bajas como resultado de la reciente crisis económica, pero, a nuestro juicio, representan una fuerza de trabajo única, en primer lugar, en condiciones óptimas de salud, y con rasgos de personalidad específicos en donde resalta, la fuerza, la resistencia, la audacia, el valor, pero sobre todo, la juventud; es decir, un grupo de migrantes mexicanos que la crisis económica y el mismo proceso de control fronterizo los selecciona como fuerza de trabajo excepcional para el capital estadounidense. El resultado de esa vulnerabilidad creada intencionalmente y que se agravará cada vez más ante las políticas persecutorias del Estado norteamericano, consiste en seleccionar entre los migrantes sólo a aquellos que reúnen las mejores cualidades de salud física y emocional como trabajadores. Esta es la verdadera función de toda esa política darwiniana cuyas respuestas evade el gobierno mexicano. Desde las prácticas "darwinianas" hoy en boga que suponen la sobrevivencia del más fuerte y que anidan también en los sentimientos nacionalistas de una gran parte de la sociedad estadounidense, se infiere que quienes en adelante crucen la frontera habrán pasado la prueba más rigurosa; serán por tanto, entre los inmigrantes, los más aptos para la economía de ese país.

El menor migrante antes mencionado, una vez capturado fue llevado a un Centro de Detención de El Pazo, Texas para su declaración de ley. El sistema de datos de la computadora registraba y comparaba sus huellas digitales comprobando que se trataba de la misma persona; indicando que ya tenía un record de dos aprehensiones previas a pesar de que había dado nombres distintos ¡No cabía duda, aunque él no veía, sus huellas lo delataban! Mientras yo permanecía callado y tratando de no expresar emociones, a él lo observo cansado y pensativo de frente a un oficial de inmigración, quien apoyándose en los archivos del sistema de datos de la Patrulla Fronteriza lo compara con los registros anteriores y con orgullo me muestra la pantalla de su computadora como si sólo se tratara de un acto de eficiencia 
tecnológica. Los datos revelaban que nació el 8 de Julio de 1990. Allí me explicaron que de reincidir y llegar a acumular un número determinado de detenciones, así sea menor de edad, será procesado y privado de su libertad. En esa ocasión sólo sería deportado a México de manera expedita, aspecto que debido a la distancia no sucedería si fuera centroamericano; en este segundo supuesto, sería trasladado a un albergue para menores. Esta observación indica que aunque frecuentemente se detiene y se deporta de manera inmediata a los menores migrantes mexicanos, cuando son reincidentes son privados de su libertad; esto es uno de los resultados que poco se conocen. Por tanto, es una falacia escuchar que entre los menores migrantes mexicanos no existen detenidos; lo que sucede es que no son atendidos por las autoridades mexicanas.

A la mañana siguiente nuestro grupo de académicos visitaría un albergue "modelo", Southwest Key Shelter for Minors de la ciudad de Phoenix, Arizona que en aquel entonces funcionaba como el principal albergue de la zona para Menores "no acompañados" de origen centroamericano. Debe subrayarse que para poder ingresar se establecieron varias condiciones que el lector debe de interpretar según su criterio: no preguntar nada a los menores, desprenderse de computadoras, celulares, cámaras, grabadoras, plumas, lápices, cuadernos. El tiempo de permanencia de los menores migrantes en los albergues sirve para procesar, deportar $u$ otorgar a terceros la custodia de los menores migrantes. Su población en ese momento era de aproximadamente 40 menores cuyas edades promedio oscilaban entre los 14 y 17 años, lo cual indicaba que con todo y sus consecuencias, se trata de un sector que es separado de los adultos. Nótese que no siempre se trata de menores migrantes "no acompañados", sino que en muchos casos son menores migrantes separados con violencia de quienes los acompañan. De cualquier forma, a distancia me pregunto por qué no observé a menores de 10 y 5 años; ¿están en otro albergue?, ¿los han dado en adopción? Esta es una de las interrogantes que en el momento de la visita no hice y que a la distancia resulta pertinente no dejar de lado en las futuras investigaciones.

El Shelter for Minors es parte de la Agencia de Jóvenes Refugiados de Estados Unidos, la cual se encarga de su financiamiento. Su personal reconoce que "todos los niños llegan asustados..." Lo primero que se hace es darles comida y asignarles una trabajadora social, quien se encargará de "explicarles" que este no es un Centro de Detención, sino un lugar muy distinto que funciona como un albergue. Más allá de lo que sucede en esos centros, lo real es que muchos de estos menores fueron separados de sus familiares durante el cruce fronterizo y se encuentran privados de su libertad. 
El trabajador o trabajadora social es también el encargado(a) de localizar a los familiares de estos menores en Estados Unidos, o en su país de origen, utilizando los medios de comunicación de alguna radiodifusora local o los servicios de la iglesia de la comunidad. En algunos casos, quienes llegan hasta ese lugar son indígenas que no hablan Español como sucede con algunos guatemaltecos. Para esto, por ley debe buscarse a alguien que pueda servir de traductor de alguna lengua particular, lo cual frecuentemente no sucede. En este caso se les deporta o se busca una familia adoptiva que en Estados Unidos quiera asumir su custodia; pero, la pregunta correcta debe ser: ¿los padres, por estar en otro país o ser indocumentados no tienen derecho a reclamar a sus hijos? Obviamente, esto está fuera de toda racionalidad sobre derechos humanos, pues ¿qué pasa cuando la custodia de éstos menores se entrega a terceros? ¿acaso eso no es un exceso del Estado liberal frente a las personas? Por supuesto, un familiar puede solicitar la custodia de uno de estos menores, pero, suele no reunir los requisitos exigidos. Las autoridades de nuestros países han renunciado a clarificar este hecho.

El Shelter for Minors cuenta con habitaciones amplias, compartidas por varios menores. Son cómodas y tienen un lugar de convivencia social con sofás y televisor. Obviamente, los menores no están recluidos formalmente en cárceles, pero, no pueden marcharse; o sea, no son albergues: son claramente centros de detención permanente.

Quienes están a cargo de esto centros no son oficiales de inmigración, sino instructores que ofrecen talleres de mecánica, pintura, música, repostería y dibujo técnico a los internos; en ese sentido esta situación ha cambiado gracias a las presiones sociales en defensa de los derechos humanos, pero no se puede generalizar y menos ahora que se reconozca que se trata de una política de abierta criminalización para perseguir a los inmigrantes.

Se percibe que este centro se reconoce como un espacio donde priva la pluralidad étnica: en las paredes del centro de detención que se menciona están desplegadas las banderas de El Salvador, Guatemala, México, Estados Unidos, etc. Llama la atención una pintura artística colgada de la pared con la imagen de un puño humano que se extiende a ambos lados desvaneciendo suavemente sus formas humanas con la leyenda: "muchos países, muchas culturas". Y es que la pintura es uno de las experiencias artísticas más sublimes que el hombre es capaz de desarrollar libremente e incluso en condiciones como las que aquí se describen (Lyotard, 1987).

Quienes están aquí recluidos teóricamente tienen derecho por ley a solicitar ir a juicio ante un Juez de Inmigración con la intención de quedarse 
a residir en Estados Unidos. En el caso comentado, existe un grupo de abogados de "Las Américas" que los asiste legalmente. Uno de los cuestionamientos de este centro es que si el familiar se encuentra residiendo como indocumentado, enfrentará serias dificultades para asumir la custodia, ya que debe mostrar solvencia económica, entrar en relación con el grupo de abogados y acudir varias veces al albergue, lo que en términos reales lo hace un blanco probable de aprehensión. Se trata de una tragedia humana porque ni los familiares son garantía de ser elegidos como "tutores"; es decir, el menor es colocado en el mayor de los desamparos, pues carece del derecho a elegir y a recibir el afecto y el amor de sus seres queridos, como lo proclaman los derechos supremos del niño; bástenos mencionar sólo uno de los artículos de la Convención sobre los Derechos del Niño relacionados al tema tratado,

ARTÍCULO 9:

Los Estados Partes velarán por que el niño no sea separado de sus padres contra la voluntad de éstos, excepto cuando, a reserva de revisión judicial, las autoridades competentes determinen, de conformidad con la ley y los procedimientos aplicables, que tal separación es necesaria en el interés superior del niño (subrayado mío). ${ }^{4}$

Una reflexión cuidadosa de esta experiencia indica que, aunque en estos centros los menores y adolescentes se muestran tranquilos, saben que su libertad, sueños de superación y trabajo han sido truncados. Por ejemplo, según lo comentó un trabajador social, un joven guatemalteco, hijo de un inmigrante indocumentado, llevó a los tribunales su caso, y a pesar de tener alta probabilidad de ganar su juicio, decidió volver a Guatemala porque sabía que su mamá estaba muy triste. Él dijo, tratando de retener el llanto: "venía a estudiar y a reunirme con mi padre, pero fracasé..." En el Shelter for Minors hizo muchos amigos y le conflictúa despedirse de ellos; y es que entre quienes comparten la misma historia es común que se establezcan relaciones intensas de solidaridad. Cuando un menor es liberado se realiza una reunión general de despedida. Una de las últimas acciones será dejar a sus compañeros un mensaje escrito en un tablero.

Dos trabajadores sociales, con un alto grado de sensibilidad humana reconocen que a estos niños les toman cariño y ello se debe a su vulnerabilidad e historia personal. Efectivamente, estos menores tratan de ingresar a Estados Unidos cargados de ilusiones, llegar a reunirse con sus familiares, trabajar con ellos y en algunos casos llevan la intensión de estudiar. Son

\footnotetext{
4 http://www.cndh.org.mx/sites/all/fuentes/documentos/Programas/Discapacidad/Conv
} $\mathrm{DNi} \% \mathrm{C} 3 \% \mathrm{~B} 1$ o.pdf 
jóvenes que no han tenido una niñez estándar, como sucede con frecuencia con todos los jóvenes migrantes. La mayoría de estos menores han trabajado sustituyendo la ausencia de su padre, otros, hijos de madres solteras, han asumido el rol de varones adultos sin serlo, etc.

Ya sin la presencia de los menores y en una situación de relajamiento un trabajador social, a pregunta de su servidor, comenta una experiencia de un joven que al llegar a Shelter for Minors lo primero que preguntó fue que cuánto tiempo iba a estar retenido en el albergue; al enterarse que por lo menos 45 días, dijo que su mamá en Guatemala se iba a morir porque estaba imposibilitada para valerse por si misma. En su comunidad él se dedicaba a tejer artesanías y con lo que vendía mantenía a su madre. Antes de llegar a Estados Unidos estuvo reuniendo dinero para el pasaje y dejar un fondo provisional a su madre. Pensaba llegar a Estados Unidos y enviarle inmediatamente dinero, pero, le tocó "la mala suerte", y entonces su principal tormento era no poder volver a Guatemala inmediatamente. Aquí hay que reconocer que en Centroamérica existe un ambiente de violencia mayor que en México y obliga a estos menores a huir de su país. Esa violencia aumentó con la deportación a esos países de los grupos de pandillas por Estados Unidos.

\section{LOS ALBERGUES EN LA FRONTERA MEXICANA}

La ubicación de los albergues para menores migrantes está relacionada con la evolución en el tiempo de los principales puntos de cruce de los migrantes mexicanos. Desde la década de 1980 y 90 Tijuana-San Diego y Ciudad Juárez-El Paso constituían los principales puntos de internación de migrantes indocumentados hacia territorio estadounidense; pero, al implementarse los primeros programas de vigilancia fronteriza, por parte de las autoridades estadounidenses, como lo fueron "Operación Guardián (1994) y la "Operación Escudo (1995) el flujo de la migración empezó a desplazarse hacia zonas más inhóspitas y menos vigiladas, complicándose más con la construcción del doble muro fronterizo, la infraestructura y el equipo tecnológico que le acompañó.

El primer albergue para migrantes menores se creó desde 1990 en la Ciudad de Tijuana, Baja California; la segunda se estableció en 1995 en Ciudad Juárez, Chihuahua; la tercera en 2000 en Piedras Negras, Coahuila, y, la cuarta en 2003 en Agua Prieta, Sonora. ${ }^{5}$ Las Casas Ymca, por su éxito

\footnotetext{
${ }^{5} \mathrm{http}: / /$ www.ymca.org.mx/prog_YMCA_mmigra.html
} 
e impacto, terminaron convertidas en un modelo pionero para estos grupos vulnerables en la frontera norte de México. ${ }^{6}$

La experiencia es como sigue:

"Personal de las Casas YMCA acude a la garita fronteriza a recoger a estos menores que en ocasiones permanecen largas horas sin poderse mover del recinto migratorio para buscar alimento, agua o descanso. La Casa les provee del ambiente hogareño, seguro y digno que les ayuda a enfrentar la dramática y desesperante realidad en la que se encuentran solos y completamente vulnerables en las agresivas ciudades fronterizas..."

A diferencia de las Casas Ymca, los albergues creados por el DIF nacional y los DIF locales correspondientes a las ciudades fronterizas entraron en funcionamiento hasta 2001. Estos fueron creados como parte de la Estrategia Interinstitucional de Atención a Menores Fronterizos que se organizó desde 1996 y que con el tiempo dio origen al Programa Interinstitucional de Atención a Niñas, Niños y Adolescentes Fronterizos en el que participaron el Sistema Nacional para el Desarrollo Integral de la Familia, la Secretaría de Relaciones Exteriores y el Instituto Nacional de Migración (Ortega Soriano, 2009). Esta estrategia transformada en programa dio origen al sistema de albergues para menores "no acompañados" deportados de Estados Unidos. ${ }^{8}$ Nótese que su enunciación es imprecisa pues pareciera que no pretendía atender a los menores deportados, sino a "niños, niñas y adolescentes fronterizos". No obstante lo anterior, sus funciones terminaron siendo una copia de las Casas Ymca:

- Les brindan alojamiento, alimentación, servicios de salud y vestido.

- Buscan y localizan a sus familiares.

- Entregan a los niños, niñas y adolescentes a los familiares que acrediten la filiación en el mismo alberge.

- En el caso de que las familias de bajos recursos que no puedan trasladarse a los estados del norte para recoger a los niños, los alberges buscan financiamiento para enviarlos a sus lugares de origen y reunificarlos con sus familias.

- Se canaliza a los niños a sus lugares de origen.

Según los datos de la red de albergues correspondientes a 2007, Nogales, Tijuana y Ciudad Juárez son los puntos de la frontera que, en orden de importancia recibieron la mayor parte de los menores migrantes deporta-

\footnotetext{
${ }^{6} \mathrm{http}: / /$ www.unicef.org/mexico/spanish/17043 12170.htm

${ }^{7} \mathrm{http}$ ://www.ymca.org.mx/prog YMCA mmigra.html

${ }^{8} \mathrm{http}$ ://www.unicef.org/mexico/spanish/17043_12170.htm
} 
dos. De las quince ciudades con albergues, en 2007 estas tres concentran 60.4 por ciento del total (Tabla 3 ).

Tabla 3: Albergues para Menores deportados, 2007

\begin{tabular}{|c|c|c|c|c|c|}
\hline \multicolumn{2}{|c|}{ Región } & \multicolumn{3}{|c|}{ Red de albergues } & \multirow[t]{2}{*}{$\begin{array}{c}\text { Población } \\
\text { atendida }\end{array}$} \\
\hline Frontera norte & & & & & \\
\hline Estado & Municipio & Albergues & DIF & ONG & \\
\hline \multirow[t]{2}{*}{ Baja California } & Mexicali & 3 & 2 & 1 & 1,027 \\
\hline & Tijuana & 4 & 3 & 1 & 4,189 \\
\hline \multirow[t]{3}{*}{ Chihuahua } & Chihuahua & 1 & 1 & & 2 \\
\hline & Ciudad Juárez & 5 & 3 & 2 & 3,151 \\
\hline & Ojinaga & 1 & 1 & & 73 \\
\hline \multirow[t]{2}{*}{ Coahuila } & Ciudad Acuña & 1 & 1 & & 326 \\
\hline & Piedras Negras & 2 & 1 & 1 & 827 \\
\hline Nuevo León & Monterrey & 1 & & & 110 \\
\hline \multirow{3}{*}{ Sonora } & Agua Prieta & 2 & & & 847 \\
\hline & Nogales & 2 & & & 5,565 \\
\hline & San Luis Río C. & 1 & & & 940 \\
\hline \multirow[t]{3}{*}{ Tamaulipas } & Matamoros & 1 & & & 701 \\
\hline & Nuevo Laredo & 1 & & & 1,624 \\
\hline & Reynosa & 1 & & & 1,396 \\
\hline \multicolumn{6}{|l|}{ Frontera sur } \\
\hline Chiapas & Tapachula & 1 & & & 488 \\
\hline Total & & & & & 21,366 \\
\hline
\end{tabular}

Entonces, por lo que aquí se señala, algunos de los padres y familiares acuden directamente a los albergues de las ciudades de la frontera a cargo del DIF a recoger a los menores, y otros escapan de dichos albergues con la intención de intentar cruzar nuevamente hacia Estados Unidos. Esto hay que clarificarlo porque algunas autoridades de distinto nivel, además de identificar erróneamente el traslado con la repatriación, equivocan las cifras al creer que el envío de los menores se hace sólo a través del INAMI y los DIF. Por lo demás, si se pretende promover una política de atención de estos menores en las comunidades de origen, es conveniente no limitarse a estas acciones. Lo que si resulta preocupante es saber qué hacen las autoridades mexicanas cuando los menores son tan pequeños que no tienen aún capacidad para dar información, y por tanto, resulta imposible localizar a sus padres o familiares (Tabla 4). 
Tabla 4: Edades de los menores atendidos por los albergues

\begin{tabular}{lrrrrrrr}
\hline Año & $00-05$ & $\%$ & $06-12$ & $\%$ & $13-17$ & $\%$ & Total \\
\hline 2001 & 155 & 2 & 747 & 9.8 & 6,718 & 88.2 & 7,620 \\
2002 & 254 & 3.8 & 894 & 13.3 & 5,560 & 82.9 & 6,708 \\
2003 & 276 & 3.8 & 768 & 10.7 & 6,150 & 85.5 & 7,194 \\
2004 & 562 & 5.1 & 1,334 & 12.2 & 9,024 & 82.6 & 10,920 \\
2005 & 883 & 4.8 & 2,429 & 13.2 & 15,069 & 82 & 18,381 \\
2006 & 821 & 4 & 2,028 & 9.9 & 17,652 & 86.1 & 20,501 \\
2007 & 550 & 2.6 & 1,771 & 8.3 & 19,045 & 89.1 & 21,366 \\
Total & 3501 & 3.8 & 9,971 & 10.8 & 79,218 & 85.5 & 92,690
\end{tabular}

Fuente: Ortega Soriano, 2009 (ver http://www.unicef.org/mexico/spanish/AnalisisP1.pdf).

No está por demás tomar en consideración que los migrantes, y con más razón cuando se trata de menores, sufren infinidad de vejaciones que tratan de "olvidar" y que en los albergues difícilmente son tratadas por los profesionales, sobre todo cuando el ambiente es de alta tensión e inseguridad.

"En el lado mexicano de la frontera, los menores de edad son tratados con una gran preocupación inicial y compasión, pero el gran deseo y búsqueda por reunificarlos con sus familias, hace que las autoridades mexicanas los regresen a sus hogares sin entender realmente aquello que los forzó a irse..."

Esta práctica está orientada por la idea de que el retorno a su lugar de origen y hogar es el único objetivo que se busca. Puede ser este el deseo general, pero, debe haber menores que por razones plenamente justificadas y no quieran regresar a su comunidad y hogar.

Después de la repatriación, el DIF procura la reunificación familiar de los niños, niñas y adolescentes migrantes sin compañía tan pronto como sea posible, sin llevar a cabo un cuidadoso análisis para estipular si la reunificación se hace conforme al interés superior del mismo. Como resultado, los niños que han huido de condiciones de explotación o abuso pueden encontrarse de regreso, con las mismas circunstancias que los obligaron a migrar a través de la frontera... (Appleseed, 2011: 19).

Frecuentemente se piensa que los menores tratan de llegar a Estados Unidos sólo en busca de reunificación familiar. Eso en general predomina, pero cuando ya son adolescentes existen otras motivaciones pocas veces reconocidas tales como: buscar trabajo, estudiar, ir a conocer, ir en búsqueda de cónyuge, huir de la delincuencia organizada, e incluso escapar de la violencia intrafamiliar, etc. Buscar trabajo es una de las condicionantes 
que inciden en aquellos sectores sociales que desde temprana edad se convierten en fuerza de trabajo, de ahí que emigrar no hace más que afirmar esa condición. En cambio, escaparse del hogar es sintomático de que esa estructura no es el espacio ideal, o como dice el pensamiento burgués, no es la "célula básica" de la sociedad en la que se forjan los hombres del mañana.

El hogar es realmente una estructura de poder, donde coexisten quienes toma las riendas y quienes simplemente obedecen. Ocasionalmente es la estructura que abre espacios para las relaciones negociadas entre sus miembros; pero también es el ámbito generador de traumas que terminan marcando de por vida a los hijos y a alguno de los cónyuges. En esas condiciones, la decisión de emigrar de los menores y adolescentes es un intento de liberación dolorosa, pero necesaria; otras veces constituye el único medio para forjar la identidad bajo relaciones de conflicto. Esto es, cuando los menores deciden tomar distancia de las relaciones que los oprimen, lo hacen obligados por las circunstancias. Y a pesar de que esta acción debe ser vista como una decisión "liberadora" e inevitable, también es difícil y dolorosa para los niños, niñas y adolescentes porque sucede, en el primer caso, en la etapa de mayores necesidades de afecto o en el segundo, en la etapa de "agitación y tormenta" (Hall, 1904) en la que el adolescente está obligado a adquirir la capacidad de deliberación, del desenvolvimiento de la identidad y de la valoración de las cuestiones éticas en la etapa de mayor coraje, esfuerzo y heroísmo de los seres humanos. De una reflexión como ésta es posible pensar en recomendaciones y propuestas que escapan a la regla:

México debe desarrollar estándares nacionales que fomenten a que el DIF tome un rol más proactivo en proveer asistencia social a los menores de edad migrantes, y protegerlos de ser regresados a ambientes que puedan arriesgar la salud física o psicológica del menor. El DIF debe llevar a cabo visitas domiciliarias en casos de posible abuso o descuido por parte de profesionales (como consejeros familiares) entrenados en cuestiones de riesgo de niños, niñas y adolescentes, y debe proveer de supervisión y asistencia en el proceso de adopción de aquellos niños huérfanos o sin tutores. El DIF debe además crear albergues especializados y programas de seguimiento para aquellos menores de edad que están en riesgo de adicción de drogas (Appleseed, 2011: 19).

Tómese como evidencia lo complicado que es este problema a partir de las experiencias vividas en Zacatecas las cuales resultan ilustrativas. El responsable en DIF-Zacatecas que se encarga de la protección de los menores no acompañados que traslada a la entidad desde la red de albergues 
de la frontera norte de México reconoce que algunos han sido abusados sexualmente y/o maltratados psicológicamente pero no se indaga en ello y en consecuencia, la reunificación familiar es muy conflictiva (Ricardo Rosales, Entrevista, 08 de Diciembre, 2014). En otros casos, la reunificación familiar es imposible y peligrosa: esta es la experiencia de un adolescente que después de ver frustrado su intento de cruzar con éxito hacia territorio estadounidense, al ser entregado a su madre, ésta se negó a recibirlo, y aunque el DIF-Zacatecas le proporcionó un máquina soldadora para facilitarle una forma de ingresos propios y disuadirlo de su deseo de emigrar, éste volvió a intentarlo dos veces, logrando en el tercer intento su objetivo. Obviamente, quería irse de su casa al precio que fuera, así tuviera que arriesgar su vida (Ricardo Rosales, Entrevista, 08 de Diciembre, 2014). En esta entrevista nos enteramos de un tercer caso de un adolescente que emigró huyendo de las amenazas de un grupo delictivo y que no logró internarse con éxito a Estados Unidos. Al igual que en el ejemplo anterior, fue trasladado a la entidad a través del DIF-Zacatecas, pero, de llevarlo al hogar su vida corría peligro, así que se decidió entregarlo a la Procuraduría del Estado buscando su protección. Por supuesto, estas y otras acciones indican no sólo lo delicado del tema, sino también, la necesidad de nuevas propuestas de política pública dirigidas a este sector social.

De lo comentado en esta última parte se deduce que no es posible que como regla general todos los menores sean simplemente regresados a sus hogares y entregados a sus padres con la idea fija de la reunificación familiar. Experiencias como las que aquí se relatan conducen a repensar las soluciones fáciles y abordar el tema con rigurosidad y con la máxima apertura en la búsqueda de alternativas no convencionales.

\section{Conclusiones}

La principal conclusión de este artículo consiste en destacar que los menores migrantes no son vulnerables por ser menores, como tampoco lo son las mujeres o los indígenas, sino que son convertidos en vulnerables y sometidos a mayores riesgos como parte esencial de la política pública promovida por el gobierno estadounidense. De hecho se puede afirmar que los migrantes o no migrantes nacen con las mismas capacidades y limitaciones en tanto seres humanos.

Como ya se señaló, ante la ausencia por parte de Estados Unidos de la suscripción de las Convenciones Internacionales sobre derechos humanos respecto de los migrantes en general y de los menores migrantes en particular, sin renunciar a estos principios, es necesario virar los reclamos 
de México exigiendo, desde el sistema consular, el apego y la aplicación de las leyes civiles por parte del sistema legal estadounidense a quien o quienes como personas e instituciones resulten responsables de maltrato, muerte y desaparición forzada. El objetivo debe conducir a evitar que sean las personas migrantes y sus hijos quienes enfrenten ellas mismas al sistema de leyes y programas del gobierno estadounidense. Este esquema de razonamiento es aplicable para ilícitos tales como el trabajo impago, la prolongación de la jornada laboral, la discriminación, la extorsión, el asesinato, etc.

Relacionado con lo anterior, México debe de emprender la defensa activa de sus menores migrantes o adultos estableciendo alianzas con los países que comparten la misma situación, en este caso con Guatemala, Honduras y El Salvador. Sin embargo, nuestro país debe comprometerse asimismo a asumir su responsabilidad en relación del desplazamiento o residencia de los migrantes centroamericanos.

Respecto de los menores deportados bajo la responsabilidad de los albergues existentes en la frontera norte de México, además de indagar y atender los abusos psicológicos y/o sexuales sufridos, es urgente revisar cuidadosamente si corren algún peligro serio, si es o no recomendable reintegrarlos a sus comunidades u hogares y en caso de que esté presente la posibilidad de algún riesgo serio, además de mantener una vigilancia permanente a través de personal especializado, es conveniente crear alguna unidad de protección y cuidado a cargo de los DIF estatales y evitar que los menores se vuelvan a convertir en víctimas.

Finalmente, es inevitable eludir el debate teórico capaz de cuestionar la política del estado de excepción que conduce al autoritarismo y a la eliminación de los derechos de los inmigrantes.

\section{REFERENCIAS BIBLIOGRÁFICAS}

Agamben, Giorgio, 2004, Estado de Excepción - Homo sacer, II, I, Traducción, Introducción y Entrevista por Flavia Costa, Adriana Hidalgo editora, Buenos Aires.

Ángel, Perla del; Flores, Esmeralda; Martínez, Lizeth; Moreno Mena, José; Navarrete, Blanca y Siu, Esmeralda, 2012, Violaciones a derechos humanos de personas migrantes mexicanas detenidas en los Estados Unidos, Segundo Informe, Programa de Defensa e Incidencia Binacional de la Iniciativa Frontera Norte de México, Fundación Ford. 
Appleseed, 2011, Niños en la frontera: evaluación, protección y repatriación de niños, niñas y adolescentes sin compañía, Reporte de Investigación financiado por Hispanics in Philanthropy, Fundación BBVA Bancomer, US-Mexico Foundation, Appleseed.

Castañeda, Alejandra, 2012, “La violencia de la ley: la legislación migratoria y el proceso de deportación”, en París Pombo, María Dolores (coordinadora), Migrantes Desplazados, Braceros y Deportados. Experiencias migratorias y prácticas políticas, El Colegio de la Frontera Norte/Universidad Autónoma de Ciudad Juárez/Universidad Autónoma Metropolitana (Unidad Xochimilco), México.

Hall, Stanley G., 1904, Adolescence: Its Psychology and Its Relations to Physiology, Anthropology, Sex, Crime, Religion, and Education, New York: D. Appleton and Company.

INEGI, 2010, Censo General de Población y Vivienda, México.

INEGI, 2015, Encuesta Intercensal, México.

Giddens, Anthony, 1993, Las Nuevas Reglas del Método Sociológico, Amorrortu, ed., Argentina.

Lyotard, Jean-François, 1987, La Condición Postmoderna. Informe sobre el saber, Ediciones Cátedra, Madrid, España.

Lorenzen Martiny, Matthew James, 2016, Migración de Niñas, Niños y Adolescentes: antecedentes y análisis de la información de la Red de Módulos y Albergues de los Sistemas DIF, 2007-2016, Consejo Nacional de Población, México.

Martínez Pérez, Pablo, 2010, La historia de Zacatecas a través de los retablos de los migrantes, Tesis de Doctorado, Unidad académica de Estudios de las Humanidades y las Artes, UAZ.

Moctezuma, M., 2013, "Retorno de migrantes a México. Su reformulación conceptual", en Papeles de Población, vol. 19, núm. 77, Universidad Autónoma del Estado de México.

Ortega Soriano, Ricardo Alberto, 2009, Análisis de los anuarios estadísticos 20012007 de la red de albergues de tránsito de niñas, niños y adolescentes migrantes, DIF/UNICEF, México

Pew Center Analysis of U. S., s/f, Customs and Border Protection, Enforcement Integrated Database records.

Rosales, Ricardo, 2014, Entrevista, 08 de Diciembre. 


\section{RESUMEN CURRICULAR DEL AUTOR}

Miguel Moctezuma Longoria

Miembro del Sistema Nacional de Investigadores, Nivel 2. Docente/Investigador de Tiempo Completo, Programa de Doctorado en Estudios del Desarrollo, Unidad Académica en Estudios del Desarrollo de la Universidad Autónoma de Zacatecas. Tiene como líneas de investigación desde la perspectiva humana: los estudios de población, las asociaciones de migrantes, las remesas familiares y colectivas, el retorno de migrantes a México y los menores migrantes. Sus escritos inspiraron musicalmente la composición de corridos, poemas, obras de teatro, pinturas y fotografías de migrantes. Entre sus aportes destacan el reconocimiento en el ámbito académico y en el diseño de las políticas públicas a partir de sus conceptos: la transnacionalidad, el migrante colectivo transnacional y el sujeto migrante. Es asimismo autor de la Ley Migrante de Zacatecas, la primera experiencia nacional en su tipo que hizo posible el reconocimiento de los derechos políticos extraterritoriales a los ciudadanos de una entidad.

Dirección electrónica: mmoctezuma@estudiosdeldesarrollo.net

Artículo recibido el 2 de agosto de 2018 y aprobado el 24 de octubre de 2018. 